\title{
Segmented Liner to Control Mode Scattering
}

\author{
Carl H. Gerhold ${ }^{1}$, Michael G. Jones ${ }^{2}$, and Martha C. Brown ${ }^{3}$ \\ NASA Langley Research Center, Hampton, Virginia, 23681
}

\begin{abstract}
The acoustic performance of duct liners can be improved by segmenting the treatment. In a segmented liner treatment, one stage of liner reduces the target sound and scatters energy into other acoustic modes, which are attenuated by a subsequent stage. The Curved Duct Test Rig is an experimental facility in which sound incident on the liner can be generated in a specific mode and the scatter of energy into other modes can be quantified. A series of experiments is performed in which the baseline configuration is asymmetric, that is, a liner is on one side wall of the test duct and the wall opposite is acoustically hard. Segmented liner treatment is achieved by progressively replacing sections of the hard wall opposite with liner in the axial direction, from $25 \%$ of the wall surface to $100 \%$. It is found that the energy scatter from the $(0,0)$ to the $(0,1)$ mode reduces as the percentage of opposite wall treatment increases, and the frequency of peak attenuation shifts toward higher frequency. Similar results are found when the incident mode is of order $(0,1)$ and scatter is into the $(0,0)$ mode. The propagation code CDUCT-LaRC is used to predict the effect of liner segmenting on liner performance. The computational results show energy scatter and the effect of liner segmentation that agrees with the experimental results. The experiments and computations both show that segmenting the liner treatment is effective to control the scatter of incident mode energy into other modes. CDUCT-LaRC is shown to be a valuable tool to predict trends of liner performance with liner configuration.
\end{abstract}

\section{Introduction}

An important element for reducing aircraft noise is the acoustic liner in the aircraft engine nacelle. The acoustic performance of a liner depends not only on the design of the liner but also on the configuration of the duct in which it is used. A previous study by Sawdy, et $\mathrm{al}^{1}$ showed that a multi-segmented liner can be used to redistribute the modes and reflect incident acoustic energy to improve liner performance. Motsinger, et $\mathrm{al}^{2}$ investigated single- and 2-stage optimized liners in a turbomachinery exhaust duct. In the 2-stage liner, the first stage is used to redistribute mode energy from the incident wave into higher order modes that are well attenuated by the second stage. The authors found that, while the improvement in noise suppression with a 2-stage liner over a single-stage at a single tone may be questionable, the increase in noise control bandwidth results in overall improved performance. In another paper, Motsinger et $\mathrm{al}^{3}$ performed an analytical and experimental evaluation of axially-segmented liners in the inlet of a model compressor. The liner configuration investigated consisted of 2 or more sections of treatment with different impedance such that reflection and scatter of acoustic energy into higher order modes occurs at the interface between adjacent sections. As in the previous study, the authors found that, while the single-stage liner may outperform the segmented liner at a specific frequency, such as the Blade Passage Frequency (BPF), the segmented liner can provide significantly improved performance over a wide band of frequencies, particularly those lower than the BPF. The authors also found that the order in which the treatment is applied does not affect the acoustic performance.

The authors of the previously cited segmented liner study ${ }^{3}$ concluded that the correlation between analytical and experimental results should be enhanced by improving: 1. acoustic source definition in the computational model in terms of magnitude and phase of the incident acoustic modes, 2. accuracy of the eigenvalue determination in the treated section of the duct, and 3. acoustic impedance determination under actual operating conditions. Significant improvements have been made in the ability to determine the mode structure in turbofan engines experimentally using a rotating rake apparatus ${ }^{4}$ and arrays of stationary

\footnotetext{
${ }^{1}$ Senior Research Scientist, Research Directorate, Aeroacoustics Branch, Associate Fellow, AIAA

${ }^{2}$ Senior Research Scientist, Research Directorate, Structural Acoustics Branch, Associate Fellow, AIAA

${ }^{3}$ Aerospace Engineer, Research Directorate, Aeroacoustics Branch
} 
microphones in the duct ${ }^{5}$ or external to the duct ${ }^{6}$. The Curved Duct Test Rig (CDTR), with which all the experimental results presented in the current paper were performed, utilizes arrays of microphones mounted in the duct upstream and downstream of the liner test section to determine the modal structure of the sound in the duct. Additionally, the CDTR is designed to generate sound with a controlled mode structure, such that the effect of mode scattering can be investigated.

Several acoustic propagation codes have been developed at NASA Langley Research Center to study the effects of sound transmission through an acoustically lined duct. One of these propagation codes, CDUCTLaRC, is used for comparison with experimental results in the current study. Accurate determination of the impedance of the liner is critical to the successful determination of sound propagating in the duct, and CDUCT-LaRC uses as input the liner impedance educed from experiments in the Grazing Flow Impedance Tube (GFIT) at NASA Langley. The GFIT, which is an upgraded version of the Grazing Incidence Tube, is a widely recognized test apparatus for determining the impedance of liners in the high flow speed and high intensity sound fields that are characteristic of turbofan applications ${ }^{7}$.

$\mathrm{Koch}^{8}$ investigated segmented liner configurations in rectangular ducts analytically. Two configurations were evaluated. The first consisted of two segments with different impedances arranged axially with the top and bottom walls lined. This is designated the two-dimensional segmentation. The second, designated the three-dimensional segmentation, consists of a segment of liner in which the top and bottom walls of the duct are acoustically treated followed by a section in which the side walls are acoustically treated. Although the number of cases investigated was limited, the analytic results showed no significant improvement of the three-dimensional segmentation over the two-dimensional segmentation. Watson, et $\mathrm{al}^{9}$ developed a method for determining the effective impedance of segmented liners in checkerboard pattern. Advancements in machining technology, including stereo-lithography, make it possible to design liners in which adjacent cells have different impedance characteristics, as one way to develop a broadband liner ${ }^{10}$. Howerton et al. ${ }^{11}$ are developing interactive tools to design and estimate the equivalent impedance of these nearly continuously variable liners.

For the current study a multi-segmented liner design is investigated in which the impedance is the same for all the liner segments. A series of experiments is performed to evaluate the effect that liner configuration has on the acoustic performance of a single degree of freedom perforate-over-honeycomb liner. The baseline configuration is asymmetric acoustic treatment, with a liner on one side of the duct and a hard wall on the opposite side. Then, with the lined wall unchanged, the ratio of liner treatment to hard wall on the opposite wall is systematically increased and the effects on mode scatter are evaluated. Each of these configurations is also evaluated computationally using the CDUCT-LaRC propagation code.

There are two purposes for this study. The first purpose is to show that the mode scattering can be controlled by the placement of segmented liner treatment. The second purpose is to demonstrate that CDUCT-LaRC is a viable tool that can be used to assess the attenuation with the segmented liner treatment.

The remainder of this paper is organized as follows. Section II is a description of the test that was performed, including both the experimental and the computational parts. A brief description of the experimental facility is also included. Section III compares the experimental and computational results for various segmented liner configurations. The results with plane waves and waves of higher mode order incident on the liner are investigated. The primary conclusions relevant to the study are included in Section IV.

\section{Description of the Test}

\section{A. Test Facility}

The CDTR is an experimental facility that is designed to assess the acoustic and aerodynamic performance of aircraft engine nacelle liners. The test section is between $25 \%$ and $100 \%$ of the scale of the aft bypass ducts of aircraft engines ranging in size from business jet to large passenger jet. The CDTR is an open loop wind tunnel that uses a fan to draw unconditioned atmospheric air through the test section. It has been described in previous papers, ${ }^{12,13}$ and readers may refer to those papers for detailed description. 
Sound is generated in the test section of the CDTR by an array of loudspeakers. The maximum sound level that can be generated in the duct is on the order of $140 \mathrm{~dB}$, which is at least $10 \mathrm{~dB}$ above fan noise for all frequencies of interest. The incident sound can be tonal or broadband. For tone noise, the magnitude and phase of the voltage signal to each loudspeaker is controlled such that a selected mode can be generated in the duct and modes not desired are suppressed. A subset of the upstream microphone array is used as the control to adjust the signals to the loudspeakers. The microphone and loudspeaker arrays and the sound control system are described in a previous paper. ${ }^{14}$ Tones are typically generated at $130 \mathrm{~dB}$ from 400 to $2400 \mathrm{~Hz}$ at $100 \mathrm{~Hz}$ increments. Sound is generated in one of the first 14 cut-on duct modes up to the $(2,2)$ mode, where the mode is expressed as (Vertical, Horizontal). The control system design ensures that the sound incident on the liner is predominantly composed of the selected mode and is at least $10 \mathrm{~dB}$ greater than any other mode in the duct. This was demonstrated previously by the authors ${ }^{13}$. The recorded signals from the upstream and downstream microphone arrays are analyzed to determine the mode distribution of the sound in the duct incident upon and discharged from the liner sample section, as discussed in previous papers. ${ }^{14,15}$

\section{B. Computational Model CDUCT-LaRC}

An integral part of the NASA Langley liner research program is the development and validation of a computational capability to predict sound propagation through flow ducts. As part of this ongoing effort, CDTR experimental data are used to validate the CDUCT-LaRC computer code, which is used to estimate the sound propagation inside an aircraft engine duct as well as radiation of sound into the far field. It was originally developed by Dougherty ${ }^{16}$ and was modified by researchers at NASA Langley Research Center. ${ }^{17}$ It is a marching method that solves sound wave propagation in a waveguide using a methodology that is based on the parabolic approximation to the convected Helmholtz equation. CDUCT-LaRC solves for the forward-traveling sound wave and ignores the reflected, backward-traveling wave. CDUCT-LaRC assumes the flow in the duct is plug flow. CDUCT-LaRC is computationally fast, which makes it particularly well suited for investigations of liner parameter variations, and the parabolic approximation is good for analysis of the curved path. In a previous paper ${ }^{15}$, researchers at NASA Langley Research Center reported preliminary results from the comparison of CDUCT-LaRC predictions to measurements taken in the CDTR.

\section{Test procedure}

The liner used in these experiments is a single degree of freedom perforate over honeycomb design. It consists of 0.75 inch deep honeycomb core covered by a 0.040 inch thick perforated plate. The plate is $8.7 \%$ open area and the holes in the plate are 0.040 inch diameter. The liner samples are 15 inch high by approximately 32 inch long in the flow direction. Liner samples form the side wall(s) of the CDTR. The flow path is 15 inch high by 6 inch wide. All tests reported here were performed with the flow speed set at Mach 0.275.

The liner described above for use in the straight flow path is given the designation L02 and the different configurations are described as follows. The asymmetric duct treatment with the liner L02 on the right hand wall and the hard wall opposite is designated L02X000 for the experimental results and L02C000 for results obtained using CDUCT-LaRC. The hard wall on the left hand wall is achieved by taping the liner on the left wall with impervious aluminum tape. Previous unpublished in-house investigations have shown that the tape simulates an acoustically "hard wall", that is, the impedance is much higher than the untaped wall throughout the frequency range. Leaving the right wall unchanged, that is, fully lined, the tape is removed from the leading $25 \%$ of the left wall. This is designated L02X025 for experiment and L02C025 for CDUCT-LaRC. In subsequent configurations, the tape is systematically removed from portions of the left wall, exposing 50\%, 75\%, and 100\%, respectively, of the liner surface. Figure 1 shows the liner sample section in the final configuration in which all tape has been removed from the left wall. 


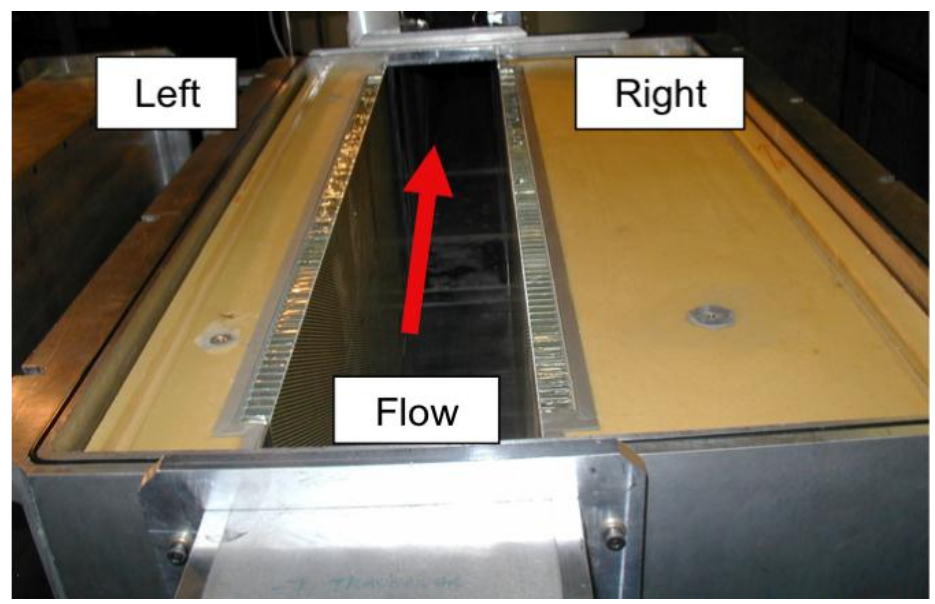

Figure 1. Liner sample section with straight liner samples on both walls, top removed, view looking downstream.

Sound in the duct is measured by one array of microphones in the hard wall duct upstream and by an identical array in the hard wall duct downstream of the liner test section. Each array is used to determine the modal amplitudes of the sound waves entering and leaving the liner test section. The sound power in each mode is calculated and summed for the total sound power. The attenuation is the difference between the sound power level upstream and that downstream of the liner test section. The derivation of the equations necessary to determine the sound power in the duct has been shown in a previous paper ${ }^{13}$.

The computer program CDUCT-LaRC is used to estimate the sound propagation in the lined duct. CDUCT-LaRC uses the liner impedance and configuration (distribution of hard wall and liner elements) as boundary conditions and the sound pressure profile in the duct upstream of the liner test section as input. The spectrum of the impedance of the liner that is being used in this test is evaluated from measurements in the GFIT ${ }^{12}$. The boundary conditions reflect the same mix of liner and hard wall as the corresponding experiment and the hard wall segments are assigned the impedance $\left(Z / \rho_{\square} c_{o} \square \square 10^{23}+i^{*} 10^{23}\right)$. The sound pressure level profile input is derived from the incident sound pressure modal amplitudes measured upstream of the liner test section in the CDTR experiment.

\section{Results}

The mode distribution plots to follow show mode distribution downstream of the liner. The authors have established previously ${ }^{12,13}$ that the desired source mode upstream of the liner test section is generally at least $10 \mathrm{~dB}$ greater than any other mode in the duct and thus, the downstream mode distribution can be considered to show the mode distribution relative to an upstream wave consisting of the source mode. The control system is programmed to generate the source mode at $130 \mathrm{~dB}$. However, depending on the frequency, the mode that is selected, and environmental conditions, the actual generated source mode sound is $130+/-2 \mathrm{~dB}$. There are as many as 14 modes cut on in the duct at the highest frequency, $2400 \mathrm{~Hz}$. In order to show the results more clearly, only the dominant mode components are plotted and the modes that do not contribute significantly to the sound downstream of the liner test section are not included in the figures. The hard wall duct cut on frequency, calculated assuming uniform flow at Mach 0.275, is included for each mode shown.

\section{A. Results with baseline configuration, L02X000 (L02C000)}

The experimental configuration L02X000 or its computational equivalent L02C000 consists of the right wall of the liner test section treated with a liner and the left wall acoustically rigid. Figure 2 shows the mode distribution downstream of the liner with the $(0,0)$ mode incident on the configuration L02X000. The $(0,0)$ mode dominates for frequencies up to $1600 \mathrm{~Hz}$ and is greatest above $2000 \mathrm{~Hz}$. Between 1600 and $2000 \mathrm{~Hz}$, where the $(0,0)$ mode is highly attenuated, the $(0,1)$ mode dominates. The figure shows that, while the incident $(0,0)$ mode is attenuated by nearly $25 \mathrm{~dB}$ at $1800 \mathrm{~Hz}$, energy is scattered from the $(0,0)$ mode to the $(0,1)$ mode, reducing the peak attenuation to approximately $16 \mathrm{~dB}$. 
Figure 3 shows the CDUCT-LaRC estimated mode distribution in the duct downstream of the liner test section with the $(0,0)$ mode incident. The mode distribution compares favorably with the measured mode distribution shown in Figure 2. The $(0,0)$ mode dominates to $1600 \mathrm{~Hz}$. The peak attenuation of the $(0,0)$ mode occurs at $1800 \mathrm{~Hz}$ and the $(0,0)$ mode is attenuated by approximately $25 \mathrm{~dB}$. Energy scatters from the

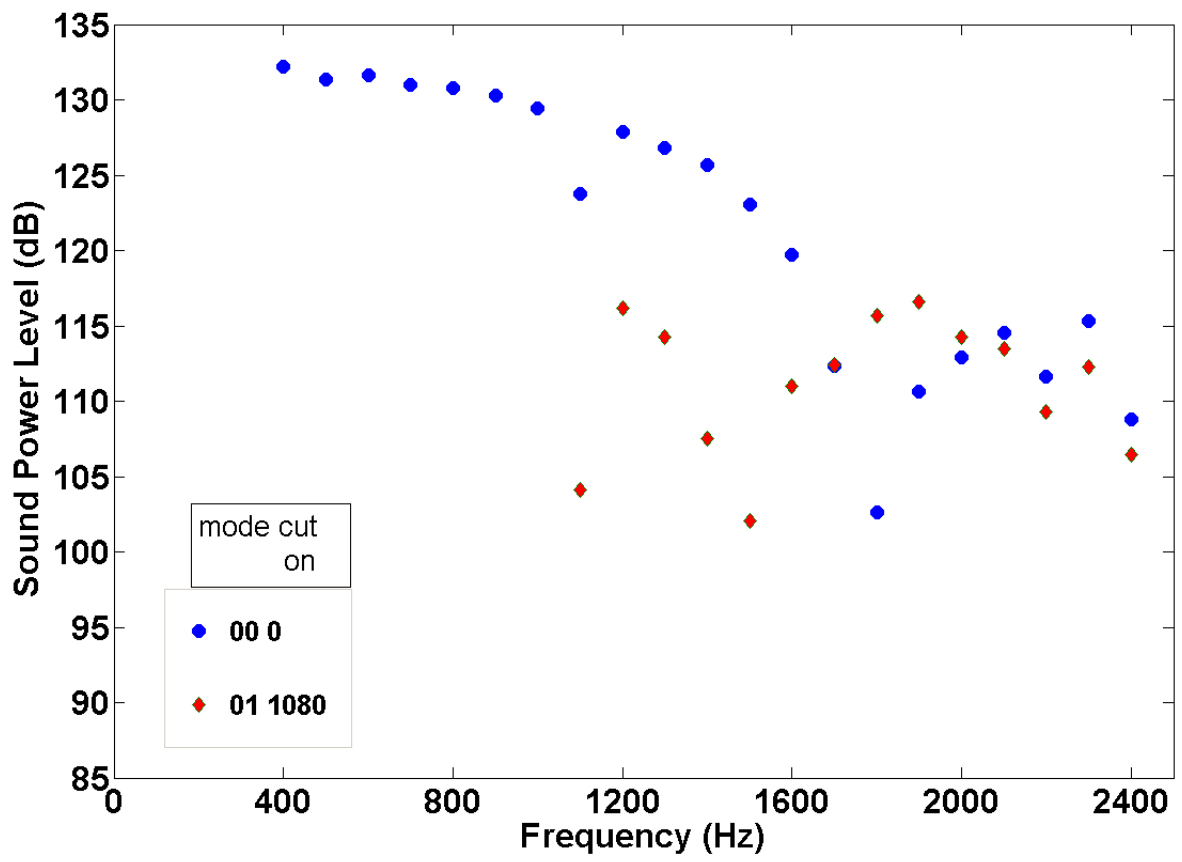

Figure 2. Measured mode distribution of sound power downstream of the liner test section, configuration L02X000, for the $(0,0)$ mode incident, Mach 0.275. Hard wall cut on frequencies of the modes are shown in the key.

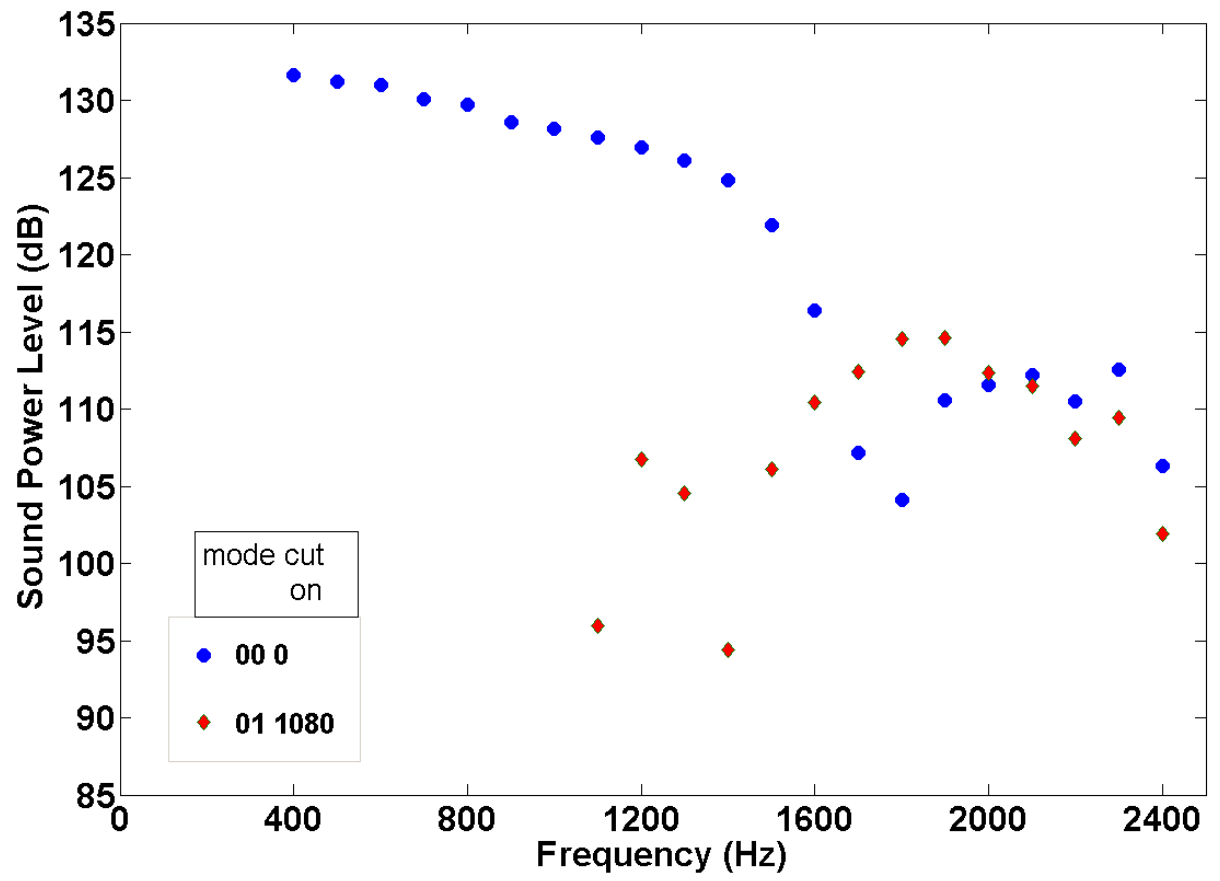

Figure 3. CDUCT-LaRC calculated mode distribution of sound power downstream of the liner test section, configuration L02C000, for the (0,0) mode incident, Mach 0.275. 
$(0,0)$ mode into the $(0,1)$ mode near the frequency of peak attenuation, reducing the overall peak attenuation to approximately $15 \mathrm{~dB}$.

When the $(0,1)$ mode is incident on the liner, energy scatters down to the $(0,0)$ mode. This is seen in Figure 4, which shows the mode distribution based on measured sound data downstream of the liner test section when the sound upstream of the liner test section consists of the $(0,1)$ mode. Since the $(0,1)$ mode cuts on at $1080 \mathrm{~Hz}$, the figure only presents results for frequencies above this cut-on frequency. From the figure, it is seen that the $(0,1)$ mode dominates in the downstream spectrum up to $2000 \mathrm{~Hz}$. Energy scatter from the $(0,1)$ mode into the $(0,0)$ mode is evident above $2000 \mathrm{~Hz}$. It is also observed, but not shown here, that when the $(1,1)$ mode is incident it scatters energy into the $(1,0)$ mode.

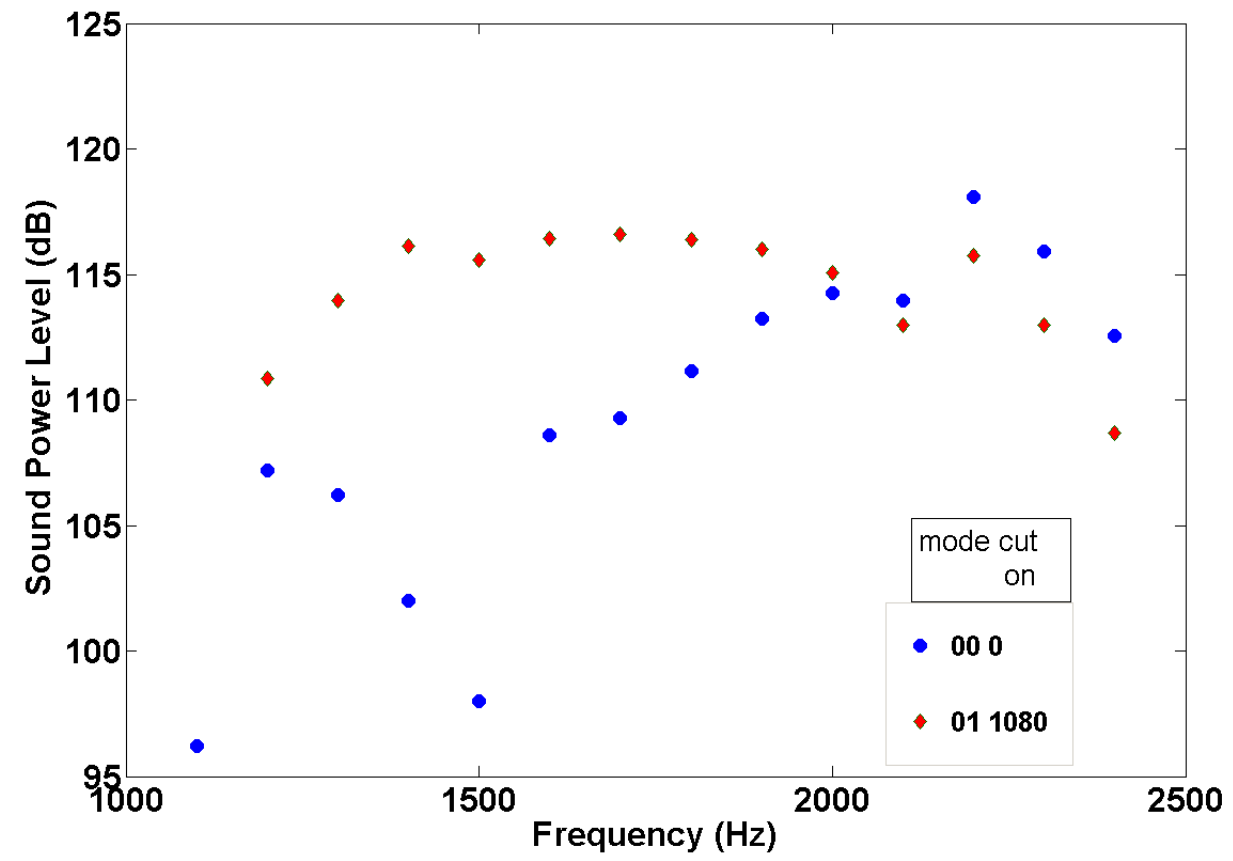

Figure 4. Measured mode distribution of sound power downstream of the liner test section, configuration L02X000, for the (0,1) mode incident, Mach 0.275 .

The mode distribution downstream of the liner test section estimated via the CDUCT-LaRC code is shown in Figure 5. The incident $(0,1)$ mode dominates up to $2000 \mathrm{~Hz}$. Energy is scattered into the $(0,0)$ mode and this mode is greatest at frequencies from $2100 \mathrm{~Hz}$ and above, as shown in Figure 5. 


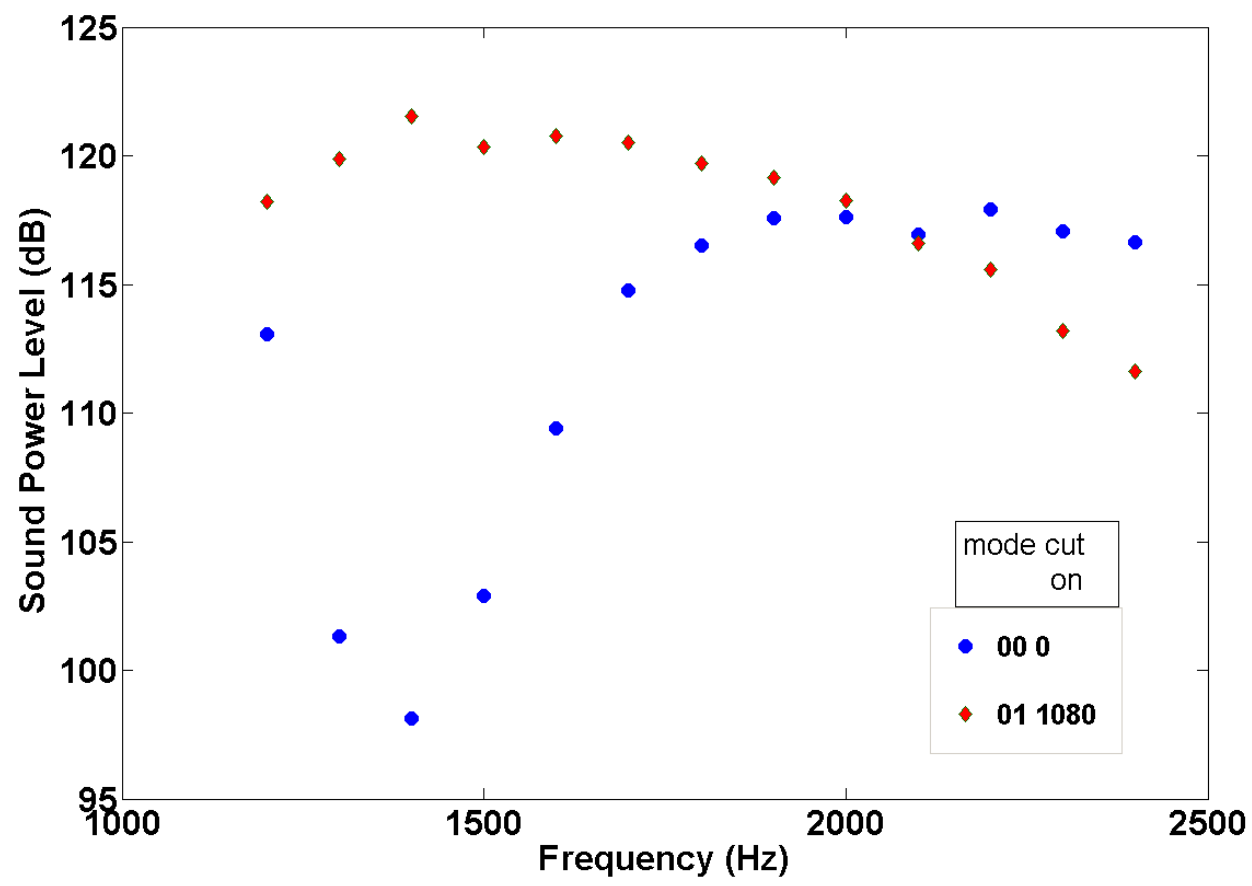

Figure 5. CDUCT-LaRC calculated mode distribution of sound power downstream of the liner test section, configuration L02C000, for the $(0,1)$ mode incident, Mach 0.275 .

Because the estimated mode distribution compares well to the measured for the cases shown, it is felt that the CDUCT-LaRC can be used to guide the process of modifying the configuration of the liner treatment in order to control mode scatter.

\section{B. Computational Results - $(0,0)$ mode incident.}

The liner impedance file (used to define the impedance at each location along the two side walls of the CDTR) is modified in CDUCT-LaRC such that the leading $25 \%$ of the left-hand wall has the same impedance as the right-hand wall, and the remaining $75 \%$ of the left hand wall is hard wall. This configuration is designated $\mathrm{L} 02 \mathrm{C} 025$ for the computational results.

The estimated mode distribution downstream of the liner test section, configuration L02C025, calculated by CDUCT-LaRC for the $(0,0)$ mode incident, is shown in Figure 6. The added liner treatment reduces the scatter of energy into the $(0,1)$ mode in the vicinity of $1800 \mathrm{~Hz}$, and reduces the overall sound at frequencies above $2000 \mathrm{~Hz}$.

When the left wall is lined on the leading 50\% and hard wall for the last 50\%, configuration L02C050, the scattering of incident $(0,0)$ mode sound into the $(0,1)$ mode is practically eliminated. The attenuation continues to shift toward higher frequencies, as shown in Figure 7.

This trend of increasing attenuation and shifting of the peak attenuation toward higher frequency continues as more of the liner is exposed on the left wall. The calculated overall attenuation with the $(0,0)$ mode incident is plotted for all the configurations, from L02C000 to L02C100 in Figure 8. The overall attenuation is calculated by subtracting the summation of the energy in each of the modes downstream of the liner test section from the sum of the energy in each the modes upstream. . 


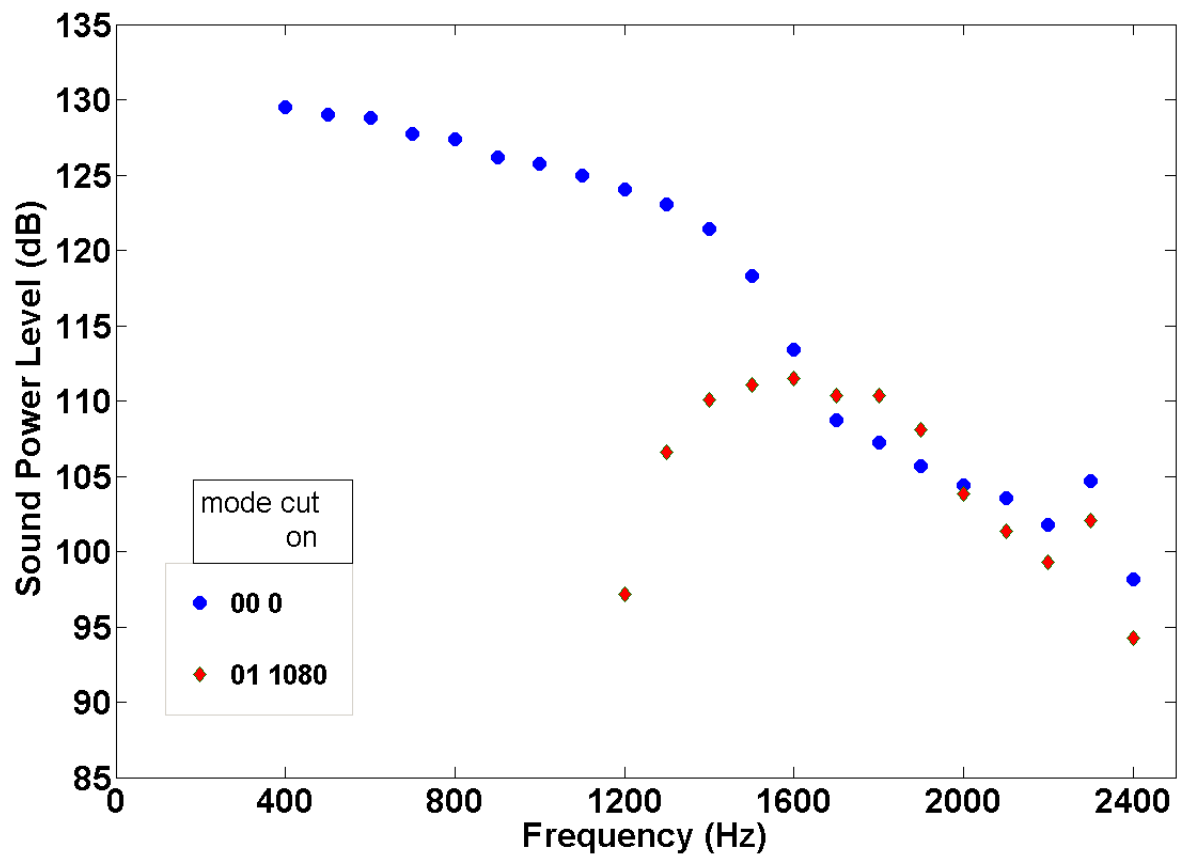

Figure 6. CDUCT-LaRC calculated mode distribution of sound power downstream of the liner test section, configuration L02C025, for the $(0,0)$ mode incident, Mach 0.275 .

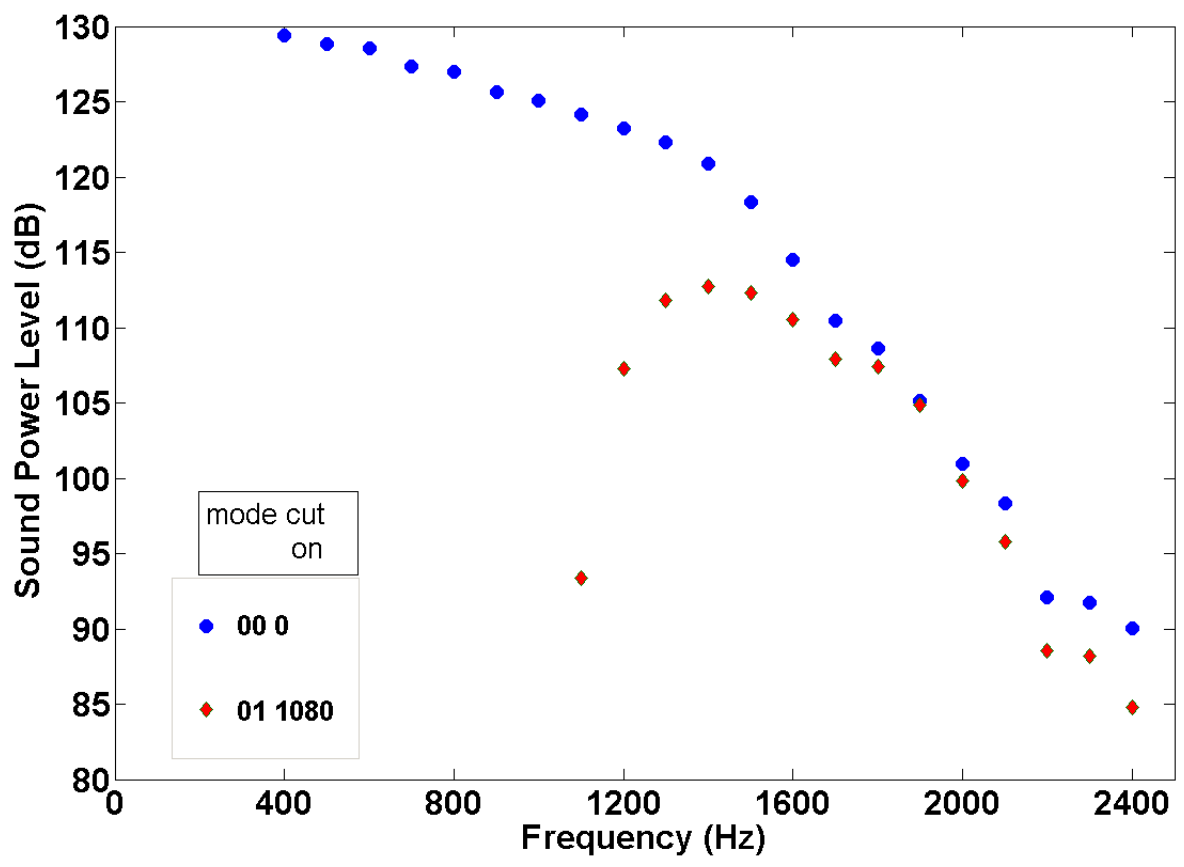

Figure 7. CDUCT-LaRC calculated mode distribution of sound power downstream of the liner test section, configuration L02C050, for the (0,0) mode incident, Mach 0.275 


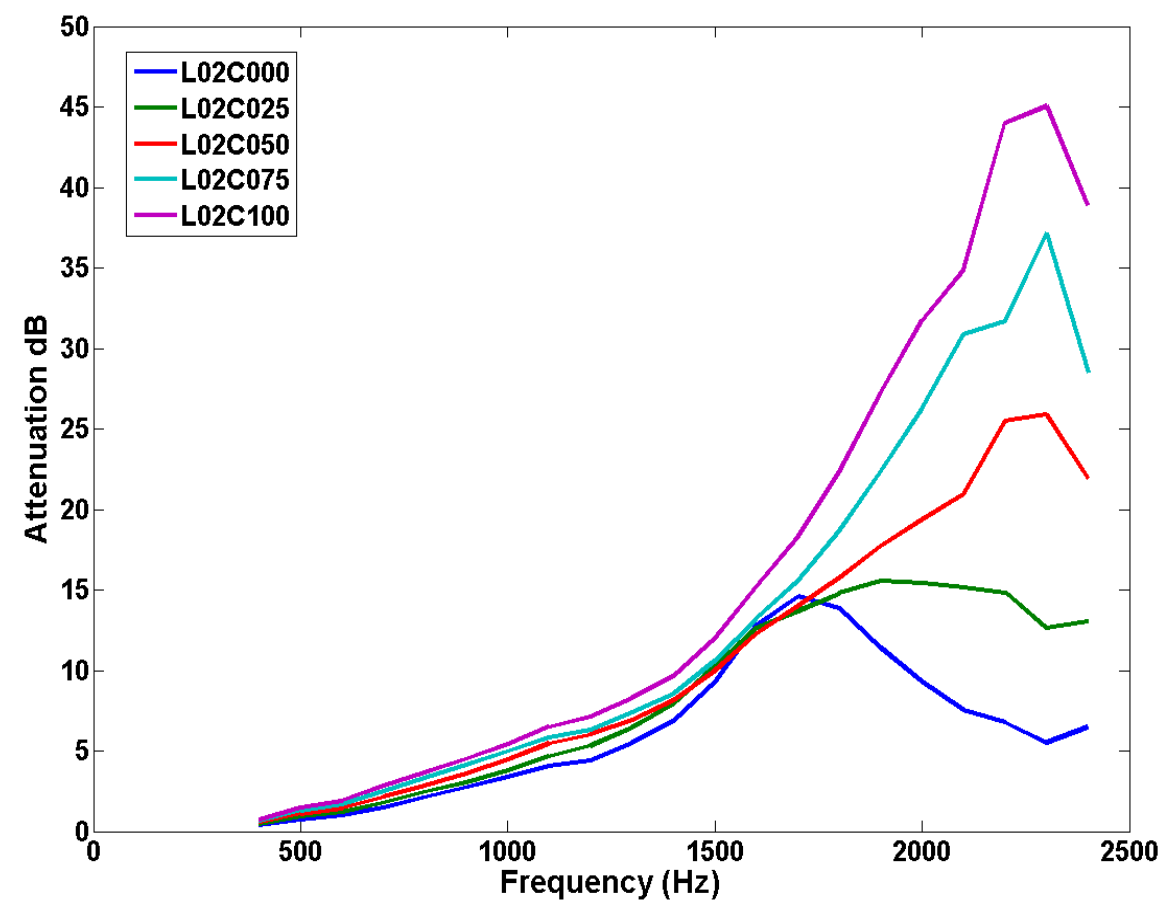

Figure 8. Variation of CDUCT-LaRC calculated attenuation with liner segment configuration, $(0,0)$ mode incident, Mach 0.275 .

\section{Experimental results - $(0,0)$ mode incident}

Figure 9 shows the mode distribution downstream of the liner based on experimental results with the $(0,0)$ mode incident at Mach 0.275 for the configuration L02X025. This is the configuration in which the leading $25 \%$ of the left wall is lined and the last $75 \%$ is hard wall. Comparing this figure to the computational results for configuration L02C025, Figure 6, it is seen that the results are comparable up to approximately $2000 \mathrm{~Hz}$, but that the measured attenuation is much greater at $2100 \mathrm{~Hz}$. This result was unexpected but a repeat run, not shown here, indicates that the results are repeatable.

The mode distribution from measurement for configuration L02X050, in which the first $50 \%$ of the left wall is lined and the last 50\% is hard wall is shown in Figure 10. This mode distribution compares favorably with the computationally derived results, shown in Figure 7, except at $2300 \mathrm{~Hz}$, where the attenuation suddenly increases.

The measured overall attenuation for the different configurations from L02X000 to L02X100 with the $(0,0)$ mode incident is plotted in Figure 11. The general trend of attenuation shifting to higher frequency and increasing in magnitude that was estimated by CDUCT-LaRC is seen in the experimental results, and the results of the experiment and computation are similar except that the measured peaks are generally broader and, in the $25 \%$ case, L02X025, the measured attenuation peaks at $2200 \mathrm{~Hz}$ and is $7 \mathrm{~dB}$ greater than computational results. In the other cases, the measured and computed attenuation peaks occur at similar frequency and agree to within $5 \mathrm{~dB}$. 


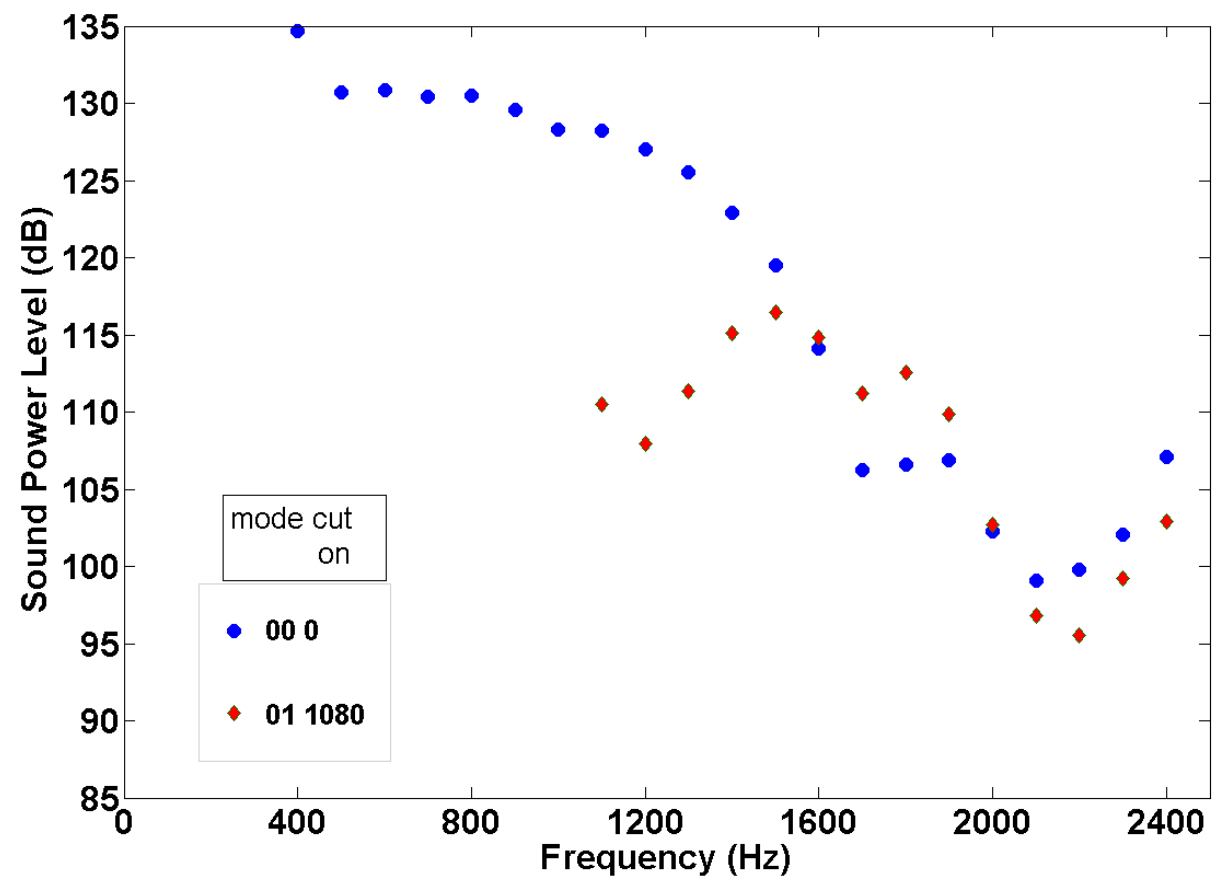

Figure 9. Measured mode distribution of sound power downstream of the liner test section, configuration L02X025, for the $(0,0)$ mode incident, Mach 0.275 .

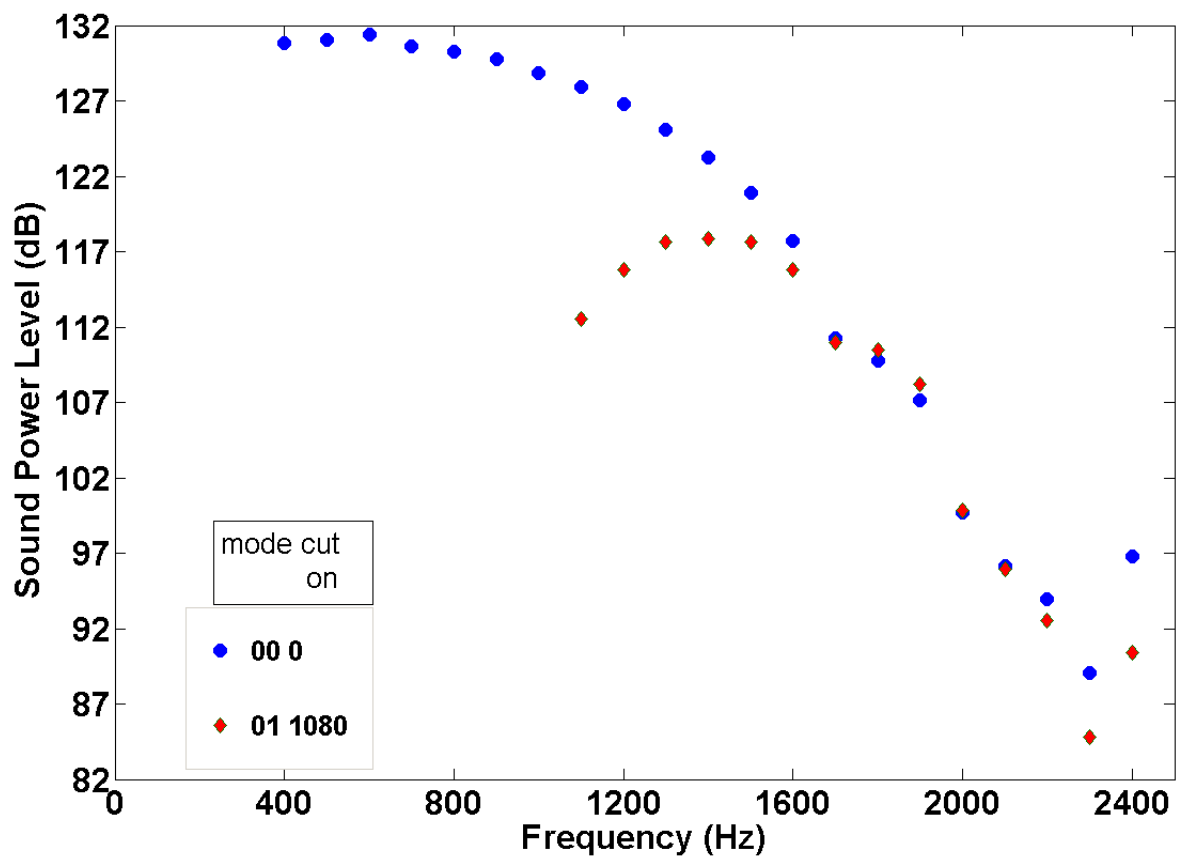

Figure 10. Measured mode distribution of sound power downstream of the liner test section, configuration L02X050, for the $(0,0)$ mode incident, Mach 0.275 . 


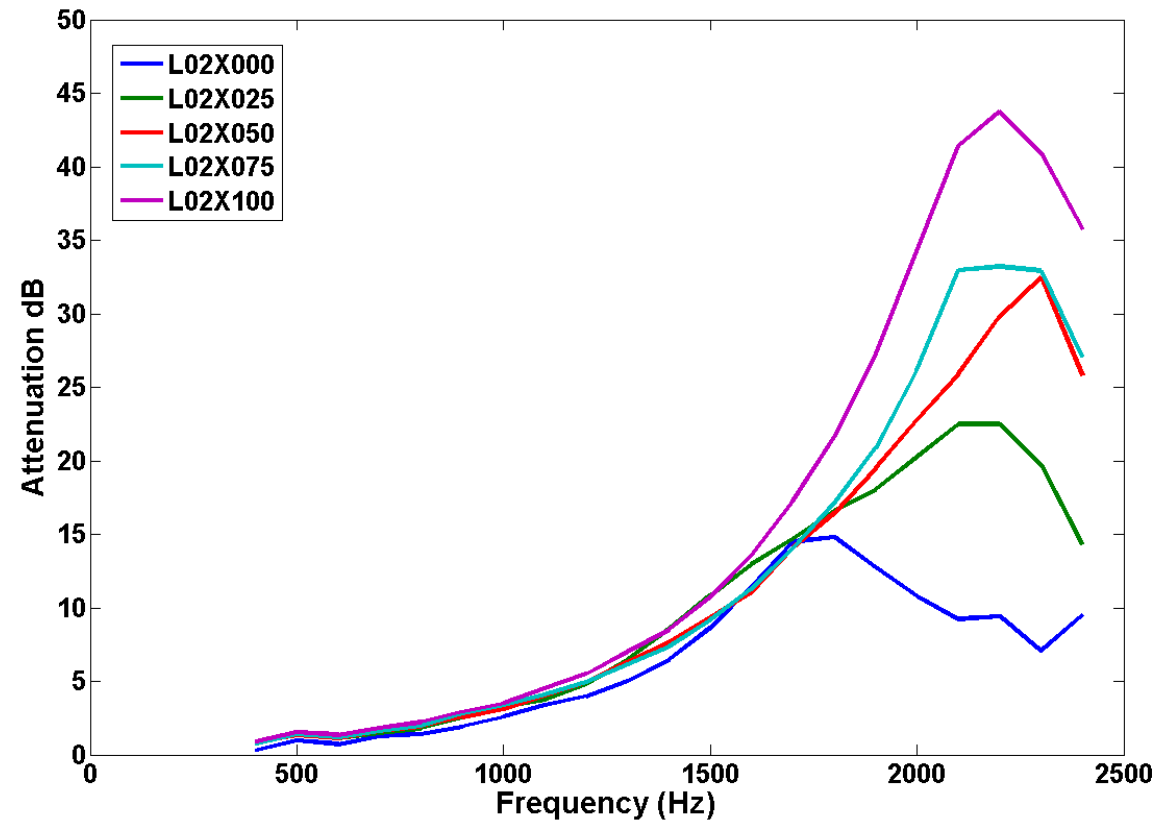

Figure 11. Variation of measured overall attenuation with liner segment configuration, $(0,0)$ mode incident, Mach 0.275.

Similar results are obtained when higher order vertical modes of the 0 -order horizontal mode are evaluated experimentally. This is shown in Figure 12, where the overall attenuation is evaluated for configurations L02X000 to L02X100 for the $(2,0)$ mode incident at Mach 0.275. The results are expected to compare to the results with the $(0,0)$ mode incident, because the lining is only on the side walls, and the top and bottom surfaces of the duct are acoustically hard.

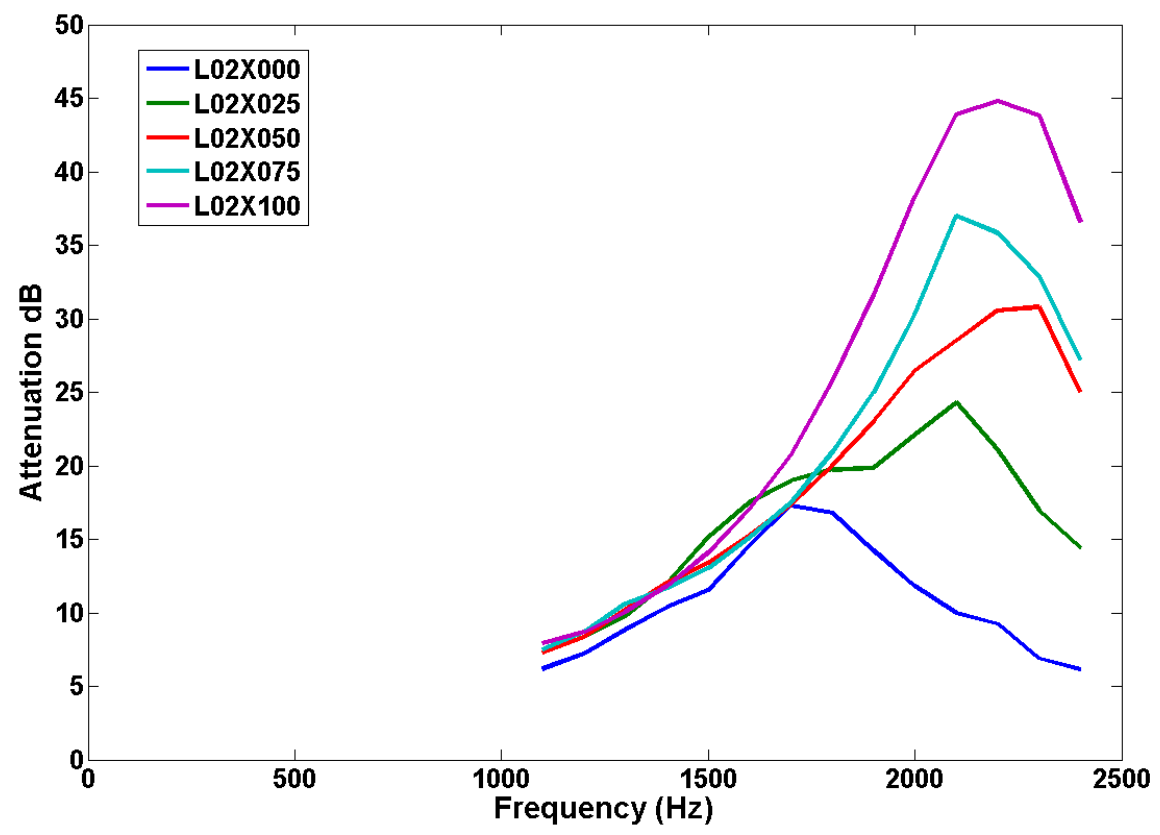

Figure 12. Variation of measured overall attenuation with liner segment configuration, $(2,0)$ mode incident, Mach 0.275 . 


\section{Computational results - $(0,1)$ mode incident}

When the incident mode and the liner treatment are both asymmetric, as is the case of the $(0,1)$ mode incident on the liner configuration L02C000, it is expected that energy will scatter into the lower order, less attenuated $(0,0)$ mode $^{18}$. This scatter was seen in Figure 5 from CDUCT-LaRC analysis. Those results show that incident $(0,1)$ mode energy scatters into the $(0,0)$ mode at frequencies above $2000 \mathrm{~Hz}$.

Introducing liner treatment to the left wall of the duct reduces the sound in the duct above $2000 \mathrm{~Hz}$. Incident energy still scatters into the $(0,0)$ mode, but the overall attenuation increases in the higher frequencies. This is shown in Figure 13, which is the computed mode distribution downstream of the liner test section for configuration L02C025 with the $(0,1)$ mode wave incident at Mach 0.275.

Energy scatter is not clear when the entire left side wall is lined, L02C100, as shown in Figure 14, so in this case, all the cut on modes are shown in the figure. The $(0,1)$ mode dominates up to $2000 \mathrm{~Hz}$. Above 2000 $\mathrm{Hz}$, no single mode dominates, but contributions from modes such as $(1,0)$ and $(2,0)$ are evident. This result is not expected since energy in the horizontal modes theoretically cannot transfer into the vertical modes. Figure 15 is plotted in order offer an explanation.

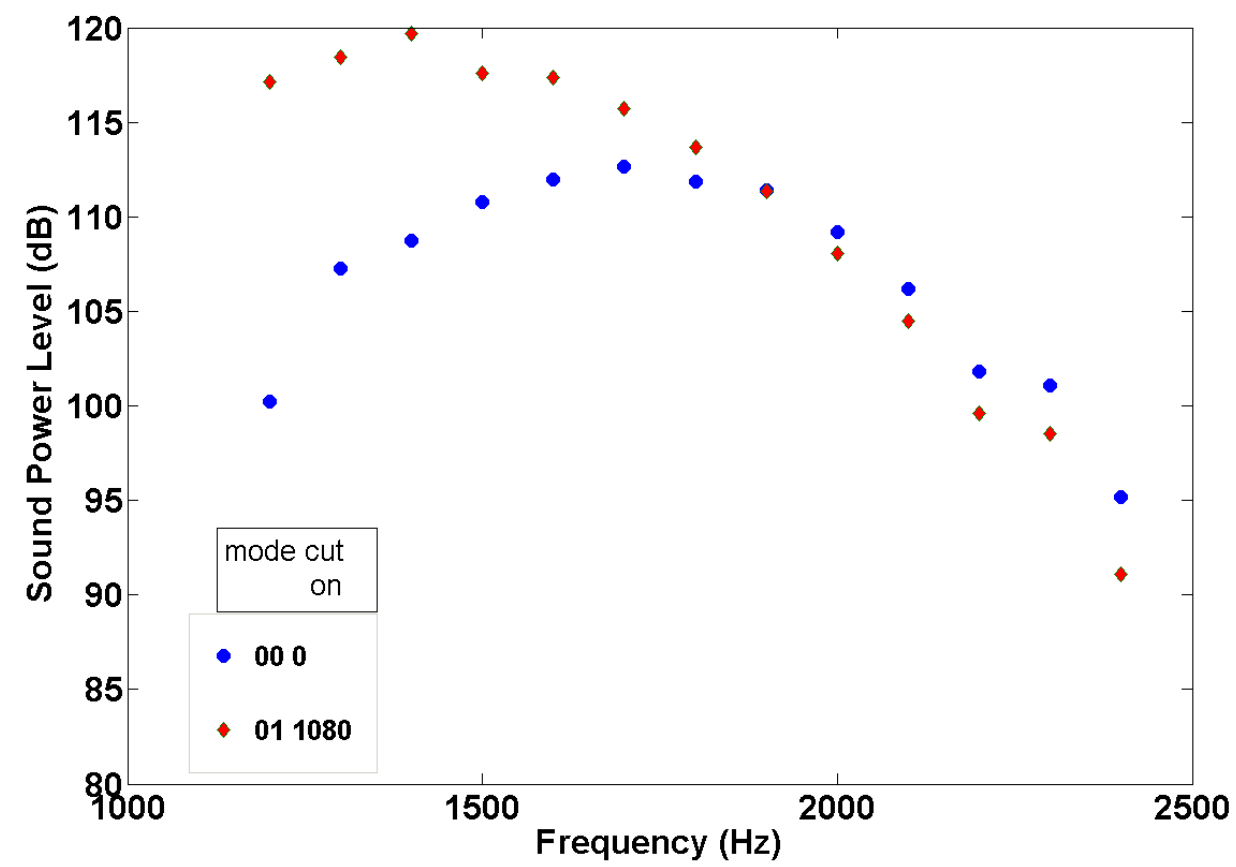

Figure 13. CDUCT-LaRC calculated mode distribution of sound power downstream of the liner test section, configuration L02C025, for the $(0,1)$ mode incident, Mach 0.275 . 


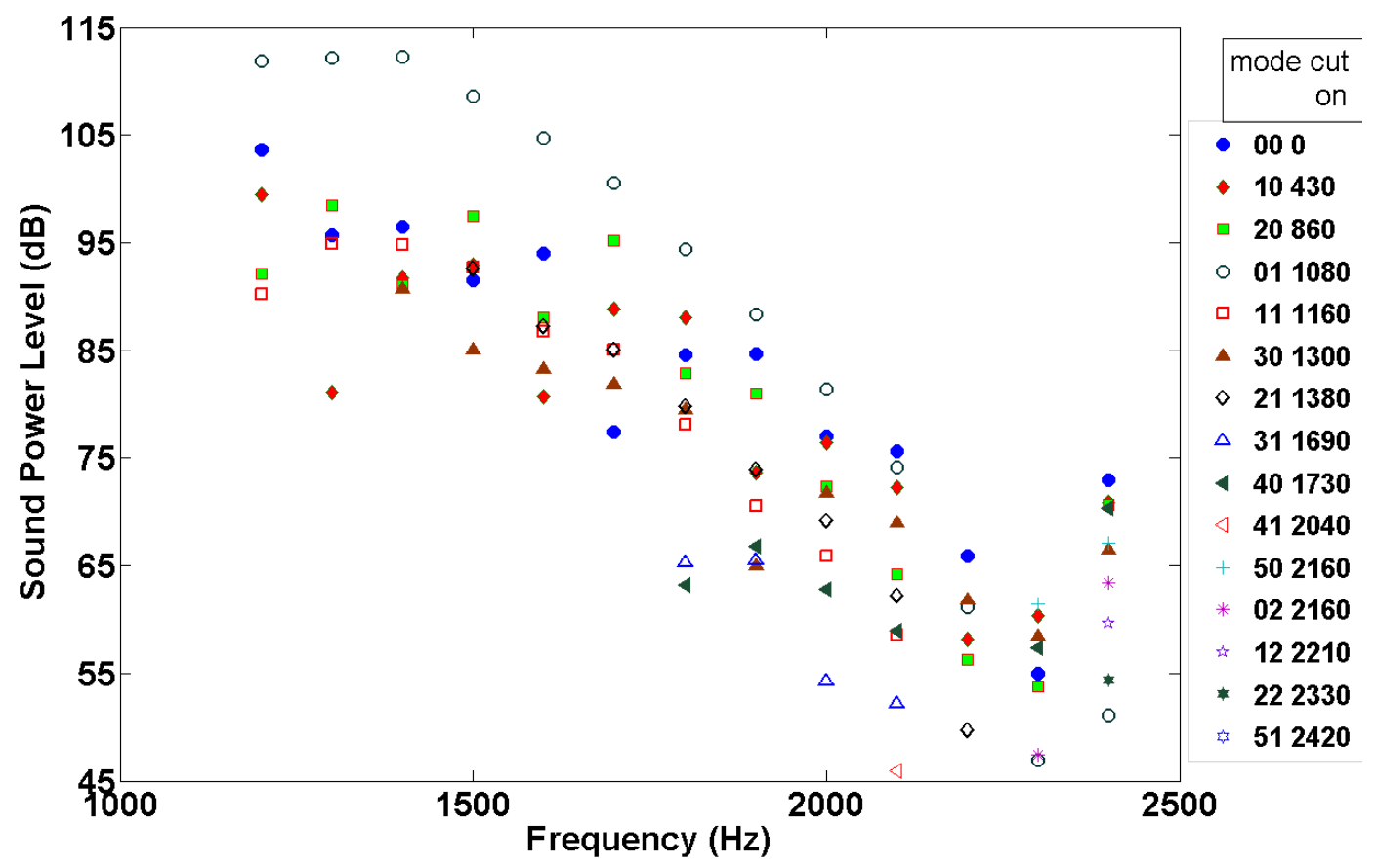

Figure 14. CDUCT-LaRC calculated mode distribution of sound power downstream of the liner test section, configuration L02C100, for the $(0,1)$ mode incident, Mach 0.275 .

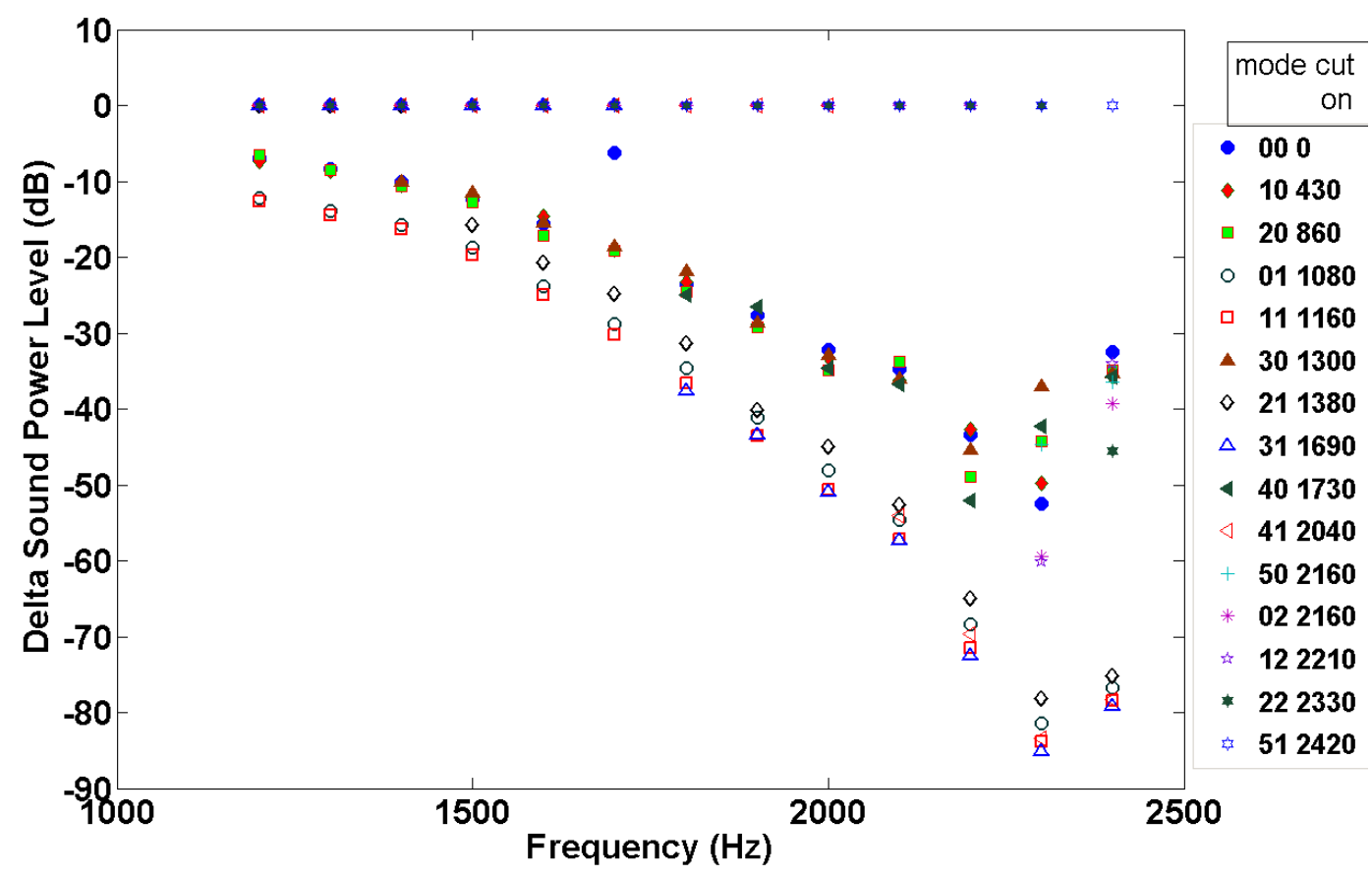

Figure 15. Calculated mode distribution of the change in sound power from upstream to downstream of the liner test section, configuration L02C100, for the $(0,1)$ mode incident, Mach 0.275.

Figure 15 shows the change in sound power level through the liner test section. The curves are determined by subtracting the sound power level for each mode upstream from the corresponding mode sound power level downstream. Therefore a negative change indicates attenuation and a positive change indicates 
amplification due to scatter. Note that modes for which 0 change is indicated are those that are cut off. The absence of positive values in Figure 15 indicates that every mode input to the liner is diminished by the liner. However, CDUCT-LaRC attenuates the symmetric modes $((0,0),(1,0)$, etc) less than the asymmetric modes $((0,1),(1,1)$, etc) by as much as $40 \mathrm{~dB}$. All modes input to the liner are between 10 to $30 \mathrm{~dB}$ less than the $(0,1)$ mode, but if some of those modes are attenuated by $40 \mathrm{~dB}$ while the $(0,1)$ is attenuated by 80 $\mathrm{dB}$, that less attenuated mode will dominate, giving the appearance that energy has scattered into it. As an example, from analysis of the upstream mode distribution not shown here, the $(1,0)$ mode energy at 2300 $\mathrm{Hz}$ is $111 \mathrm{~dB}$ entering the liner test section. It is attenuated by $50 \mathrm{~dB}$, as seen in Figure 15 , so it is $61 \mathrm{~dB}$ downstream of the liner, and that is one of the strongest modal components at $2300 \mathrm{~Hz}$. Thus, CDUCTLaRC accurately indicates that all modes are attenuated and mode scatter into vertical modes does not occur.

Figure 16 shows the computed overall attenuation for the different configurations from L02C000 to L02C100 with the $(0,1)$ mode incident. The peak attenuation increases with increasing liner treatment area, as was the case with the $(0,0)$ mode incident. The attenuation increases uniformly with the amount of treatment, and the peak attenuation at $100 \%$ left wall treatment is estimated to be $>60 \mathrm{~dB}$. There is no clear frequency of peak attenuation for $\mathrm{L} 02 \mathrm{C} 000$, but the peak gradually becomes more distinct as the amount of left wall liner increases.

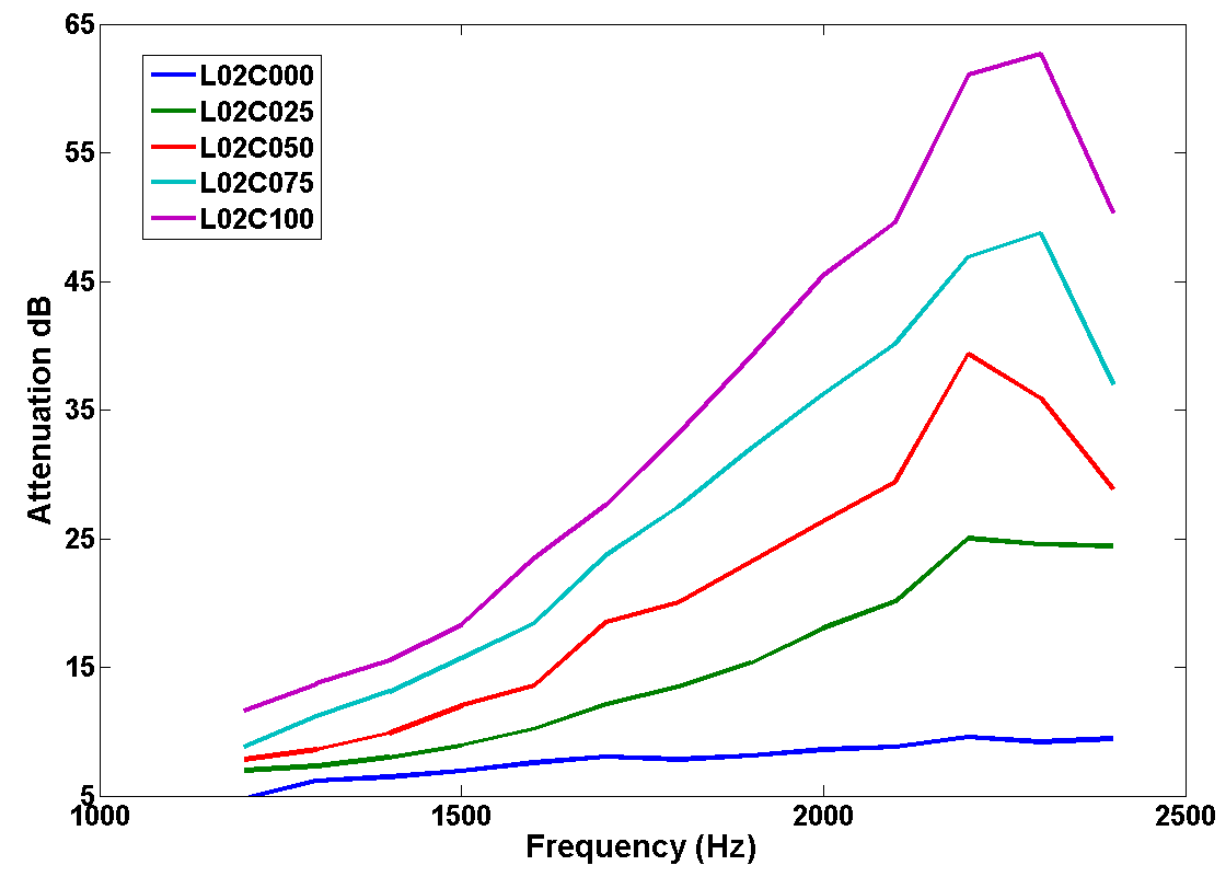

Figure 16. Variation of CDUCT-LaRC computed overall attenuation with liner segment configuration, (0,1) mode incident, Mach 0.275.

\section{E. Experimental results - $(0,1)$ mode incident}

The mode scatter from the incident $(0,1)$ mode into the $(0,0)$ mode was seen in the experimental results. The measured mode distribution for the case in which the right wall is lined and the left wall is acoustically hard, designated L02X000, was shown in Figure 4 and the results from the computation, L02C000, were found in Figure 5 to be comparable.

Figure 17 shows the mode distribution from measured sound data for the $(0,1)$ mode incident on liner configuration L02X025, in which the leading $25 \%$ of the left wall is lined. The experimental results compare favorably with the computed results, shown in Figure 13 . The $(0,0)$ mode is dominant above 1900 $\mathrm{Hz}$, but the overall energy is reduced at the higher frequencies. 
Figure 18 shows the downstream mode distribution when the entire left wall is acoustically treated, L02X100, and the $(0,1)$ mode is incident. Energy is scattered into the $(0,0)$ mode as expected and also into the next higher horizontal mode $(0,2)$. This scatter was not foreseen by CDUCT-LaRC, and this discrepancy will be the subject of further investigation.

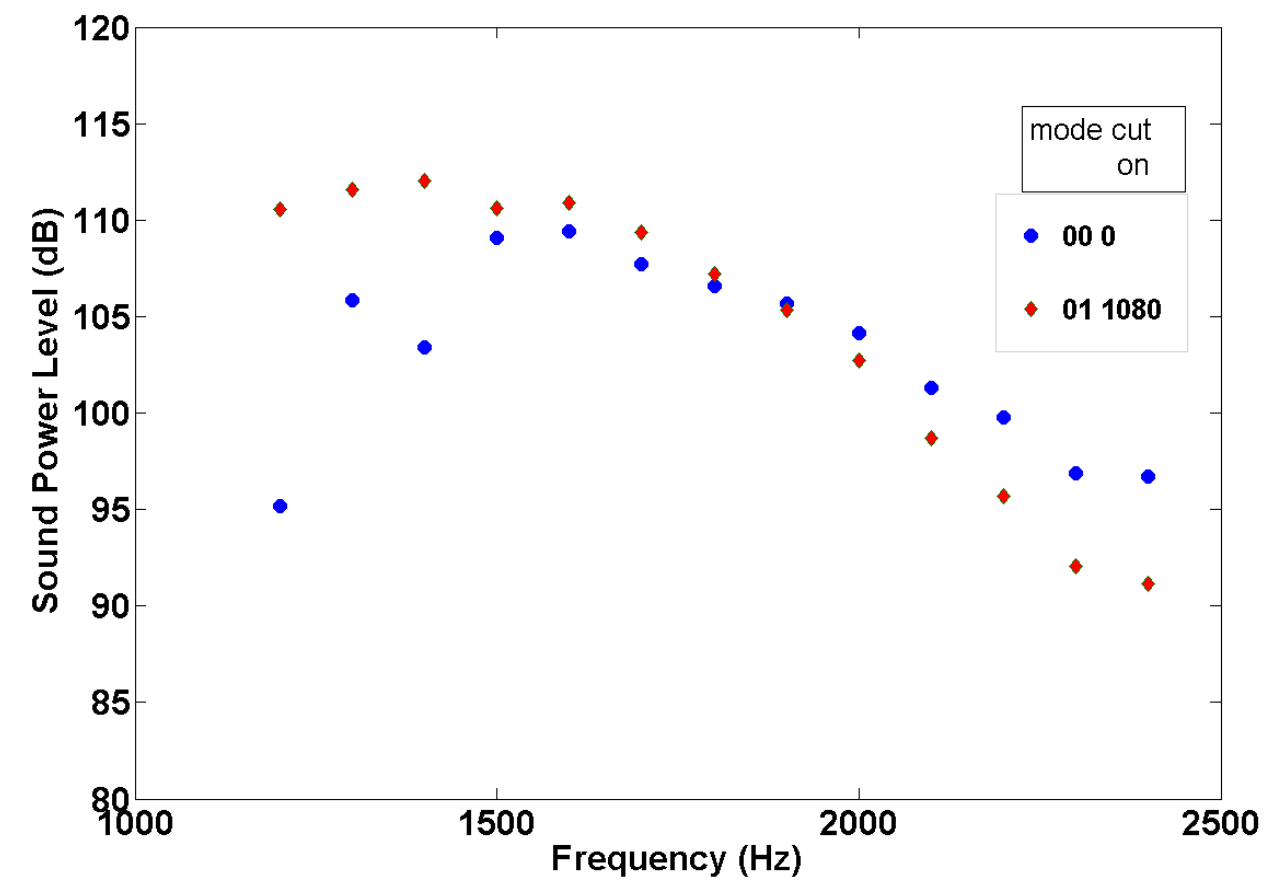

Figure 17. Mode distribution from measurement of sound power downstream of the liner test section, configuration L02X025, for the $(0,1)$ mode incident, Mach 0.275 .

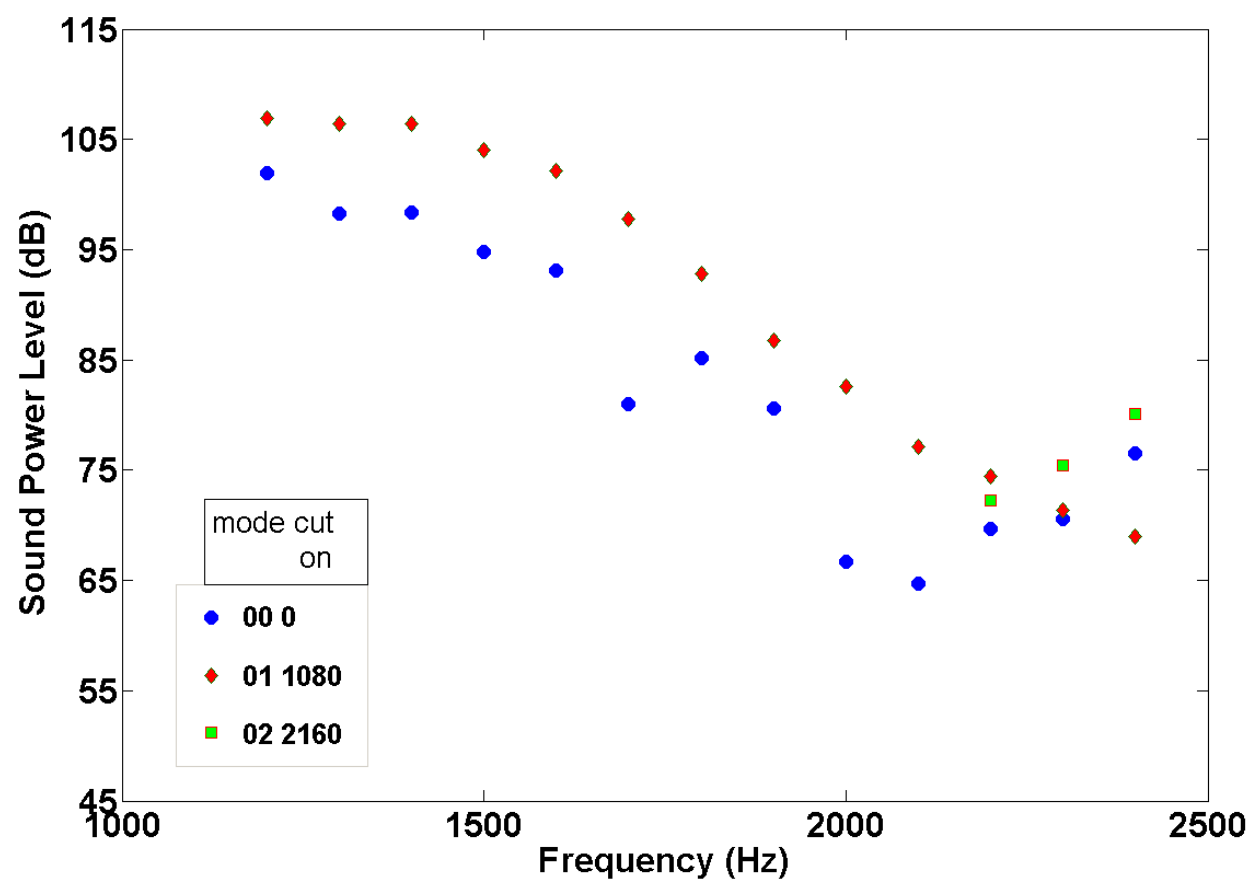

Figure 18. Mode distribution from measurement of sound power downstream of the liner test section, configuration L02X100, for the $(0,1)$ mode incident, Mach 0.275 . 
Figure 19 shows the measured overall attenuation for the different configurations from L02X000 to L02X100 with the $(0,1)$ mode incident. The overall attenuation curves steepen as more of the left wall liner is exposed and the increase of peak attenuation is slightly higher than the computational results up to $50 \%$. Above $50 \%$ left wall liner, the measured peak attenuations are not as great as those estimated by CDUCTLaRC. The maximum measured attenuation, for L02X100 is $48 \mathrm{~dB}$; where the maximum computed attenuation, for $\mathrm{L} 02 \mathrm{C} 100$, is more than $60 \mathrm{~dB}$. It is possible that the noise floor in the duct limits the maximum measurable attenuation.

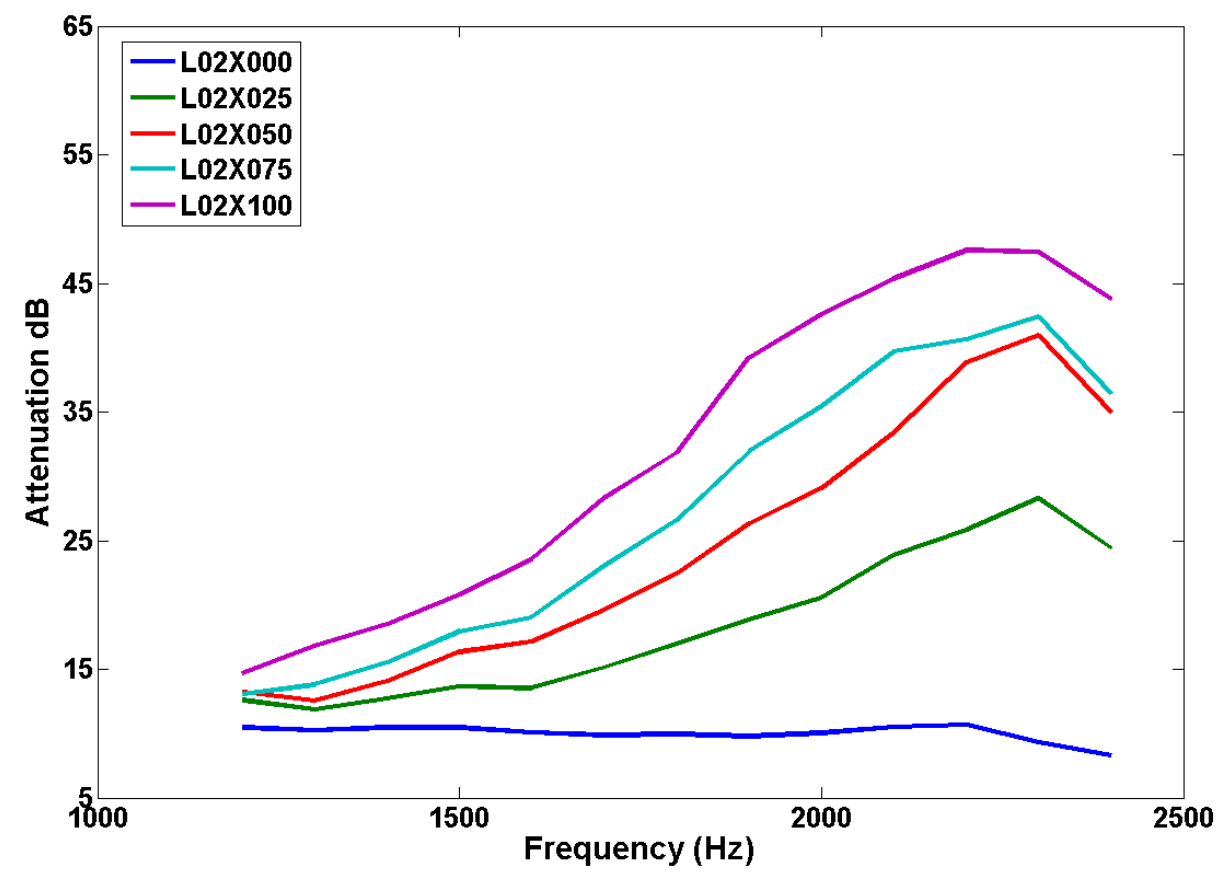

Figure 19. Variation of overall attenuation based on experimental data with liner segment configuration, $(0,1)$ mode incident, Mach 0.275 .

\section{F. Summary of Results}

Table I summarizes the results shown in the preceding figures for the $(0,0)$ mode incident at Mach 0.275 . The overall sound level spectra upstream and downstream of the liner have been summed up into 1/3octave band sound levels in the table. The 1/3-octave band attenuation is determined for the configurations evaluated and the measured results are compared to those obtained from the CDUCT-LaRC analysis. Both the measured and computational results show that the attenuation is relatively constant for all configurations at $1600 \mathrm{~Hz}$. The magnitude of the peak attenuation increases and the frequency of peak attenuation shifts upward for measured and computational results. Experimental results show that lining the

Table I. Summary of 1/3-Octave Band attenuation of $(0,0)$ mode incident on segmented liner at Mach 0.275. Compares measured to computed analysis.

\begin{tabular}{|l|l|l|l|l|l|l|l|}
\hline \multicolumn{4}{|l|}{ Measured Data } & \multicolumn{4}{l|}{ CDUCT-LaRC Analysis } \\
\hline & $\mathbf{1 / 3 - O c t a v e}$ Band Frequency & & \multicolumn{1}{l|}{$\mathbf{1 / 3 - O c t a v e ~ B a n d ~ F r e q u e n c y ~}$} \\
\hline Config & $\mathbf{1 6 0 0}$ & $\mathbf{2 0 0 0}$ & $\mathbf{2 5 0 0}$ & Config & $\mathbf{1 6 0 0}$ & $\mathbf{2 0 0 0}$ & $\mathbf{2 5 0 0}$ \\
\hline L02X000 & 10.2 & 11.6 & 8.1 & L02C000 & 10.3 & 9.9 & 6.1 \\
\hline L02X025 & 11.6 & 18.5 & 17.5 & L02C025 & 11.0 & 15.2 & 12.9 \\
\hline L02X050 & 10.3 & 19.9 & 29.1 & L02C050 & 10.9 & 18.0 & 23.4 \\
\hline L02X075 & 10.3 & 20.9 & 30.3 & L02C075 & 11.5 & 22.0 & 31.0 \\
\hline L02X100 & 12.1 & 26.0 & 38.8 & L02C100 & 13.1 & 26.3 & 40.9 \\
\hline
\end{tabular}


left wall shifts the frequency of peak attenuation from the $2000 \mathrm{~Hz}$ band to the $2500 \mathrm{~Hz}$ band and the computation shows the peak shifting upward through two 1/3-octave bands, from 1600 to $2500 \mathrm{~Hz}$. Both the experimental and computational results show that, even though area of the liner has doubled, the peak attenuation increases more than two-fold. The measured peak attenuation is greater than computed at 25\% and $50 \%$ at 2000 and $2500 \mathrm{~Hz}$. The results derived from measured data compare very favorably with the computationally-derived results for higher percentage of liner exposure on the left side.

Table II summarizes the 1/3-octave band attenuation for the $(0,1)$ mode incident at Mach 0.275 . The 1/3octave band attenuation is determined for the configurations evaluated and the measured results are compared to those obtained from the CDUCT-LaRC analysis. Both the measured and computational results show that the attenuation increases at all frequencies as the amount of left wall liner increases. The measured attenuation increases faster than computed from 0 to $50 \%$ left wall liner, but the growth rate slows at higher per cent liner coverage in comparison to computed. This may mean that the sound in the duct is approaching the noise floor.

Table II. Summary of 1/3-Octave Band attenuation of $(0,1)$ mode incident on segmented liner at Mach 0.275. Compares measured to computed analysis.

\begin{tabular}{|l|l|l|l|l|l|l|l|}
\hline Measured Data & \multicolumn{9}{l|}{ CDUCT-LaRC Analysis } \\
\hline & $\mathbf{1 / 3}-$ Octave Band Frequency & & \multicolumn{3}{l|}{ 1/3-Octave Band Frequency } \\
\hline Config & $\mathbf{1 6 0 0}$ & $\mathbf{2 0 0 0}$ & $\mathbf{2 5 0 0}$ & Config & $\mathbf{1 6 0 0}$ & $\mathbf{2 0 0 0}$ & $\mathbf{2 5 0 0}$ \\
\hline L02X000 & 10.1 & 10.2 & 9.3 & L02C000 & 7.5 & 8.6 & 9.3 \\
\hline L02X025 & 14.1 & 20.4 & 26.6 & L02C025 & 10.4 & 17.2 & 24.5 \\
\hline L02X050 & 17.7 & 29.3 & 38.3 & L02C050 & 13.9 & 24.9 & 31.5 \\
\hline L02X075 & 19.5 & 32.7 & 39.7 & L02C075 & 18.0 & 33.3 & 40.2 \\
\hline L02X100 & 23.1 & 38.9 & 46.0 & L02C100 & 21.3 & 39.8 & 53.6 \\
\hline
\end{tabular}

\section{Conclusions}

When a symmetric mode is incident on an asymmetric liner configuration, energy scatters into the nearest asymmetric mode. For the horizontal 0 -order mode incident, energy scatters into the higher, horizontal 1order mode, predominantly in the vicinity of the frequency of peak attenuation. When an asymmetric mode is incident on an asymmetric liner configuration, energy scatters into the nearest symmetric mode. For the horizontal 1-order mode incident, scatter is into the lower, less attenuated horizontal 0 -order mode. The data acquired in the CDTR demonstrate the scatter of energy from the incident mode into other modes, and it was shown that this energy transfer reduces the overall attenuation of the liner configuration. By modifying the configuration of the duct, in this case, adding segments of liner to the wall opposite the original liner, the scattered energy is suppressed, so that the net noise attenuation increases. The peak attenuation when the opposite wall is completely lined is more than twice the peak attenuation when the opposite wall is rigid, even though the total amount of liner is doubled. The segmentation in this experiment also showed that the frequency at which the peak attenuation occurs can be modified by the configuration of the liner over at least one 1/3-octave band.

CDUCT-LaRC produces results that compare favorably with the experiment. CDUCT-LaRC accurately predicts mode scatter due to the liner configuration. The computation properly shows the trend of changes in attenuation that can be expected due to modifications to the duct configuration. It shows that mode scatter can be controlled by the configuration of the segmentation. It shows the upward shift in frequency and increase in magnitude of attenuation as the percentage of liner exposure increases. While differences are noted between the computationally derived attenuations and the experimental results, CDUCT-LaRC is shown to be a valuable tool to estimate the acoustic performance of a liner configuration.

\section{Acknowledgements}

The authors are grateful for contributions made to the successful completion of this project by the laboratory technician staff and in particular Christal Kellam of NASA LaRC and Jerry Lyle of Lockheed- 
Martin Engineering Services for experiment set-up and data collection. The authors further acknowledge Brian Howerton for his support in development of the instrumentation and data acquisition systems. NASA's Subsonic Fixed Wing (now Fixed Wing) Project of the Fundamental Aeronautics Program funded this work.

\section{References}

1. Sawdy, D.T., Beckmeyer, R.J., and Patterson, J.D., "Analytical and Experimental Studies of Optimum Multisegment Phased Liner Noise Suppression Concept”, NASA CR-134960, May, 1976.

2. Motsinger, R.E., Kraft, R.E., Zwick, J.W., Vukelich, S., Minner, G.L., and Baumeister, K.J., "Optimization of Suppression for 2-Element Treatment Liners in Turbomachinery Exhaust Ducts", NASA CR 134997, April, 1976.

3. Motsinger, R.E., Kraft, R.E., Paas, J.E., and Gahn, B.M., "Analytical and Experimental Studies of Acoustic Performance of Segmented Liners in a Compressor Inlet", NASA CR-2882, September 1977.

4. Sutliff, D.L., "Rotating Rake Turbofan Duct Mode Measurement System", NASA/TM-2005-213828, October 2005.

5. Gerhold, C.H., "Determination of Fan Inlet Duct Mode Structure Using In-duct Microphone Array Measurement", presented at 141st meeting of the Acoustical Society of America, June 4-8, 2001.

6. Lan, J. and Premo, J., "Inlet Mode Measurements with an Inflow Control Device Microphone Array", AIAA 2002-2563, 2002.

7. Jones, M.G., Watson, W.R., Tracy, M.B., and Parrott, T.L., "Comparison of Two Waveguide Methods for Educing Liner Impedance in Grazing Flow", AIAA Journal, vol. 42, no. 2, pp. 232-240, February, 2004.

8. Koch, W., "On The Attenuation of Sound by Three-Dimensionally Segmented Acoustic Liners in a Rectangular Duct", NASA Technical Memorandum 80118, June 1979.

9. Watson, W.R., Robinson, J, Parrott, T.P., and Jones, M.G., "Design and attenuation properties of periodic checkerboard liners", AIAA paper 2003-3309, June, 2003.

10. Jones, M.G., Howerton, B.M., and Ayle, E., "Evaluation of Parallel-Element, Variable-Impedance, Broadband Acoustic Liner Concepts", AIAA-2012-2194, June, 2012.

11. Howerton, B.M., Jones, M.G., and Buckley, J., "Development and Validation of an Interactive Liner Design and Impedance Modeling Tool”, AIAA-2012-2197, June, 2012.

12. Gerhold, C., Brown, M., Jones, M., and Howerton, B., "Configuration effects on Liner Performance", AIAA Paper 2012-2245, June, 2012.

13. Gerhold, C.H., Brown, M.C., Jones, M.G., and Howerton, B.H., "Report on Recent Upgrades to the Curved Duct Test Rig at NASA Langley Research Center", AIAA Paper 2011-2896, June, 2011.

14. Gerhold, C., Cabell, R, and Brown, M., "Development of an Experimental Rig for Investigation of Higher Order Modes in Ducts", AIAA Paper-2006-2637, May, 2006.

15. Gerhold, C.H., Brown, M.C., Jones, M.G., Nark, D., and Howerton, B.M., "Configuration Effects on the Acoustic Performance of a Duct Liner", AIAA paper 2008-2977, May, 2008.

16. Dougherty, R. P., "A Parabolic Approximation For Flow Effects On Sound Propagation In Nonuniform, Softwall, Ducts", AIAA paper 99-1822, 1999.

17. Nark, D., Watson, W., and Mani R., "Investigation Of A Parabolic Iterative Solver For ThreeDimensional Configurations", AIAA paper 2007-3539, May, 2007.

18. Kraft, R.E., "Theory And Measurement Of Acoustic Wave Propagation In Multi-Segmented Rectangular Flow Ducts", report number R77AEG585, General Electric Technical Information Series, Oct. 1977. 